\title{
Implementation of a Service-Oriented Architecture for Applications in Phussical Rehabilitation
}

\author{
Implementación de una arquitectura con orientación a servicios para \\ aplicaciones en rehabilitación física
}

Implementação de uma arquitetura com orientação a serviços para
aplicações em reabilitação física

Fecha de recepción: 24 de mayo de 2017

Fecha de aceptación: 23 de julio de 2017

John Alexander Camacho*
Cristian David Chamorro"**
John Alexander Sanabria ${ }^{* * *}$
Nayiver Gladys Caicedo
José Isidro García

\section{Abstract}

Currently, the interest in service-oriented architectures (SOA) has risen due to their structural flexibility, which allows to obtain features such as scalability, fault tolerance, low coupling, and easy integration, among others. In this context, this article presents the implementation of a SOA for tele-operated physical rehabilitation applications; this SOA ensures an effective orchestration of services, adding special functions, such as synchronous tele-operation of machines for physical rehabilitation, in such a way that it can be adapted and implemented by using information and communication technologies (ICT). The implementation of the architecture was validated by means of a test that allowed to analyze the behavior of the web services defined for the application.

Keywords: Architecture; Physical rehabilitation; Service-Oriented; Tele-rehabilitation; Web services.

\section{Resumen}

Actualmente, se ha despertado gran interés por las Arquitecturas Orientadas a Servicios (SOA), dado que ofrecen una flexibilidad estructural que permite obtener escalabilidad, tolerancia a fallos, bajo acoplamiento y fácil integración, entre otras características. En este contexto, este artículo presenta la implementación de una arquitectura con orientación a servicios para aplicaciones de rehabilitación física teleoperada, la cual asegura una efectiva orquestación de los servicios, adicionando funciones especiales, tales como la teleoperación síncrona de máquinas de rehabilitación física, de tal manera que pueda ser adaptada e implementada por medio del uso de tecnologías de la información y las

* M. Sc. Universidad del Valle (Cali-Valle del Cauca, Colombia). john.camacho@correounivalle.edu.co. ORCID: 0000-0003-3623-9913.

** Ph.D. Universidad del Valle (Cali-Valle del Cauca, Colombia). cristian.chamorro@correounivalle.edu.co. ORCID: 0000-0002-1792-4555.

*** Ph.D. Universidad del Valle (Cali-Valle del Cauca, Colombia). john.sanabria@correounivalle.edu.co.

****Ph.D. Universidad del Valle (Cali-Valle del Cauca, Colombia).nayiver.gladys.caicedo@correounivalle.edu.co.

*****Ph.D. Universidad del Valle (Cali-Valle del Cauca, Colombia). jose.i.garcia@correounivalle.edu.co. 
comunicaciones (TIC). La implementación de la arquitectura se valida por medio de una prueba que permite analizar el comportamiento de los servicios web que fueron definidos para esta aplicación.

Palabras clave: Arquitectura con orientación a servicios; Rehabilitación física; Servicios Web; Tele-rehabilitación.

\section{Resumo}

Atualmente, tem-se despertado grande interesse pelas Arquiteturas Orientadas a Serviços (SOA), já que oferecem uma flexibilidade estrutural que permite obter escalabilidade, tolerância a falhos, sob acoplamento e fácil integração, entre outras características. Neste contexto, este artigo apresenta a implementação de uma arquitetura com orientação a serviços para aplicações de reabilitação física teleoperada, a qual assegura uma efetiva orquestração dos serviços, adicionando funções especiais, tais como a teleoperação síncrona de máquinas de reabilitação física, de tal maneira que possa ser adaptada e implementada por meio do uso de tecnologias da informação e as comunicações (TIC). A implementação da arquitetura se valida por meio de uma prova que permite analisar o comportamento dos serviços web que foram definidos para esta aplicação.

Palavras chave: Arquitetura com orientação a serviços; Reabilitação física; Serviços Web; Telereabilitação. 


\section{INTRODUCTION}

The service-oriented architecture (SOA) is a paradigm of architectures that allows to design and develop distributed computing systems, in such a way that makes it easy to create scalable and weakly coupled systems [1]posing new challenges to fulfill growing requirements for reusability, interoperability, flexibility and reconfigurability. The adoption of service-oriented architectures (SOAs. These features enable the modularity and availability of a certain functionality as a service; that is, a computational system is formed by the integration of applications and services through standardized protocols [1] posing new challenges to fulfill growing requirements for reusability, interoperability, flexibility and reconfigurability. The adoption of service-oriented architectures (SOAs. A web service (WS) is an example of this type of architecture [2], which is based on a set of norms that include Simple Object Access Protocol (SOAP), Web Services Description Language (WSDL), Universal Description, and Discovery and Integration (UDDI), to support the autonomy and the interoperability between applications developed in different programming languages and running on different platforms or operating systems [3] clinical environments, and the electronic health record. Standards are emerging to support clinical information collection, exchange and management and to overcome information fragmentation and actors delocalization. Heterogeneity of information sources at patients' homes calls for open solutions to collect and accommodate multidomain information, including environmental data. Based on the experience gained in a European Research Program, this paper presents an integrated and open approach for clinical data interchange in cardiac telemonitoring applications. This interchange is supported by the use of standards following the indications provided by the national authorities of the countries involved. Taking into account the requirements provided by the medical staff involved in the project, the authors designed and implemented a prototypal middleware, based on a service-oriented architecture approach, to give a structured and robust tool to congestive heart failure patients for their personalized telemonitoring. The middleware is represented by a health record management service, whose interface is compliant to the healthcare services specification project Retrieve, Locate and Update Service standard (Level 0. These applications offer autonomy and independence from the operating system where they are executed. In this context, this approach provides a structural flexibility that makes it possible to configure new functionalities in the system, integrating and coordinating the delivery of new services [1]posing new challenges to fulfill growing requirements for reusability, interoperability, flexibility and reconfigurability. The adoption of service-oriented architectures (SOAs. For example, different projects based on SOA have been submitted in applications of tele-operation of physical devices, such as appliances and unmanned vehicles, among others [4], where the term tele-operation creates an integrated environment, which defines a series of commands contained in a communication channel that allows the action of the physical device regardless of its geographic location [4].

One of the challenges for SOA in this type of applications focuses on the specification of the choreography and/or orchestration of the services that integrate the tele-operation system, which determine, for instance, what the messages are and how they will produce the interactions between the services involved in the development of the tele-operated implementation $[5,6]$. Focusing on tele-operation oriented toward human rehabilitation have resulted in several advances in communication technology, such as telemedicine and tele-rehabilitation. Telemedicine is defined as the exchange of medical information, from a point/site to another by means of electronic communications, with the goal of improving the health status of an individual [7]QoS (Quality of Service. This term is related to tele-health, which incorporates the concepts of health care management, education, and medical computing; tele-health provides technological solutions addressed to implement health-oriented applications (e.g., integrated information health systems at the hospital or organizational levels, electronic clinical history, etc.) [7]QoS (Quality of Service. On the other hand, telerehabilitation is based on technologies for intervening and remotely supporting persons with disabilities, which implies that the patient can be taken care of in a location different to the health center, for example, their own residence.

In this context, this article develops the implementation of a SOA for a tele-operated rehabilitation system by means of web services, which enables the integration and orchestration of both hardware and software elements that make up this application. In this article, section 2 describes the machine used for the teleoperated rehabilitation system; section 3 presents 
the developed services that constitute the SOA; section 4 describes the integration of services and their interaction within the SOA; section 5 reports the results of the integration of services; and finally, section 6 presents the conclusions.

\section{TeChNical assistance}

The technical assistance used for physical rehabilitation has control subsystems, security and power based on the configuration of a modular architecture, where each one of the electronic cards that make up the technical assistance have a specific function, which allow scalability and reuse of the components of the system (Fig. 1).

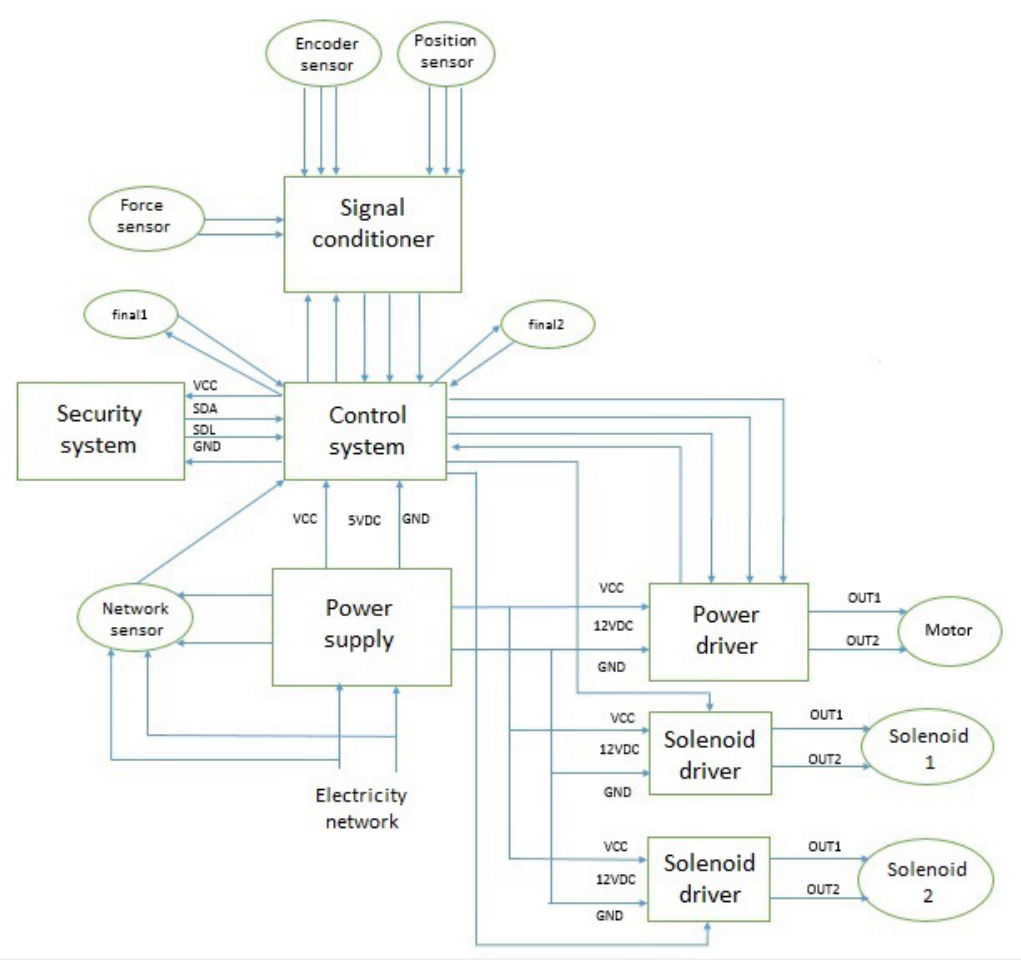

Fig. 1. Block diagram of the electronic system of the technical assistance.

Fig. 2 depicts the elements that constitute the technical assistance. The technical assistance presents several innovations with respect to [8-11]; for example, the ability to run two types of therapies: passive and active, which are required to perform a cycle of rehabilitation of a joint [12]. In the passive therapy, the motor-reducer induces movement in the patient's joint, whereas in the active therapy, the motor-reducer is uncoupled by means of an electronic clutch, and a controllable resistance is induced by means of a magnetic brake, allowing the patient to strengthen the muscles and recover the force in the affected member. 


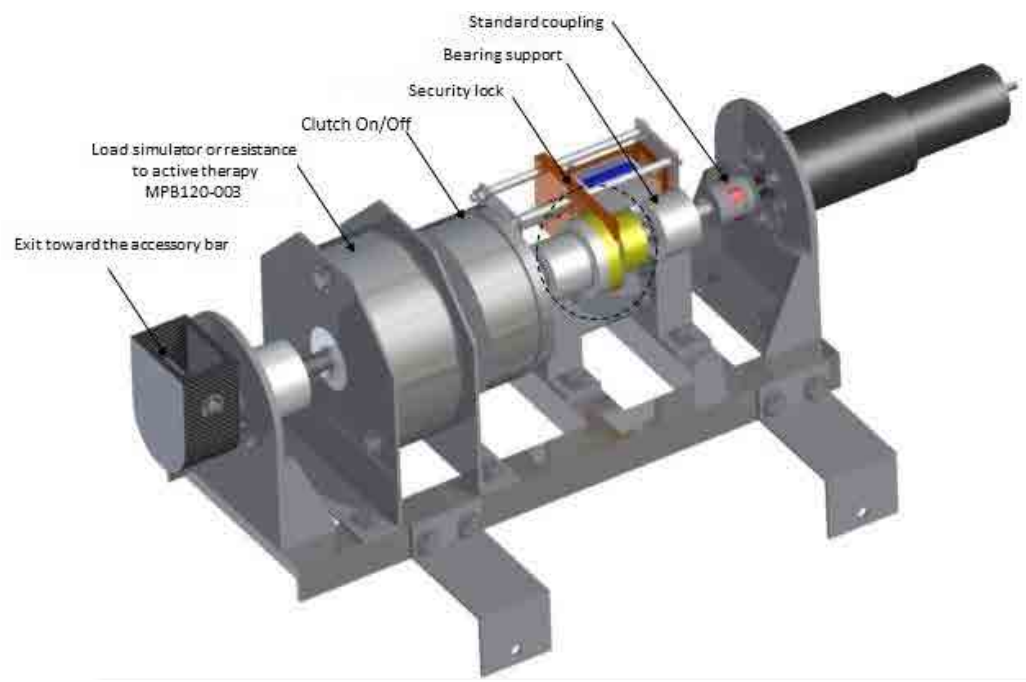

Fig. 2. Elements of the technical assistance [13, 14].

\section{WEB SERVICES}

This section presents in a methodological way each one of the services that were developed and considered necessary to construct the architecture oriented toward an application in tele-medicine, under the modality of tele-operation in physical rehabilitation. The services that were developed are the following:

- User authentication. There are two direct users: the specialist and the auxiliary. This authentication is carried out with respect to the information stored in the database. The function of this service is to look for and authenticate users according to their role.

- Patient search. This service consists in searching patients in the database assigned for this purpose and extracting three types of information: 1 ) the patient's personal information, 2) the information associated with an order for a rehabilitation clinic, and 3 ) the information related to the rehabilitation therapy history.

- Clinical history update. In the tele-medicine processes, it is very important the management of the information because it includes the patient's evolutionary process, the performed treatments, and the data on the patient's recovery. In the process of physical rehabilitation, it is necessary to know the behavior of the patient during the therapies, in order to prevent or reduce to the minimum the functional and physical consequences. The implementation of this service allows collecting both qualitative and quantitative information that facilitate tracing the history and evolution of the therapies carried out by each patient in rehabilitation. This service allows updating each session's information for every patient; the specialist can search this information, and can compare the protocol assigned at the beginning of the session with the exercises achieved by the patient at the end of the therapy session.

- Communication service. This service is essential because it grants access to the technical assistance of the tele-operated rehabilitation system, so it makes possible to carry out tasks or operations defined by the technical assistance in a physical rehabilitation therapy. This service maintains a permanent communication between the system and the technical assistance, logging in any type of event that may put at risk the physical integrity of the patient.

\section{Integration of Web Services}

The objective of the SOA is to perform physical human knee rehabilitation by means of tele-operation of technical assistance through the internet. The goal is to integrate the four web services previously described, which interact with two web applications with different privileges, each depending on the type of user (specialist or auxiliary). This application starts with the authentication of the auxiliary, who should enter the login information and password; independently, 
the specialist may start the authentication process in an asynchronous way; when the two users are correctly authenticated by the system through the authentication service, a communication channel between them is created using the communication service. It should be noted that since the creation of such channel, the communication will be synchronous. Subsequently, the auxiliary enters the identification number of the patient, and the patient search service extracts the information associated with such number; the specialist then visualizes this information and generates a rehabilitation protocol, which is stored in the patient's medical history by means of the clinical history update service; with this information the tele-rehabilitation session starts, during which the technical assistance continuously monitors and stores the information on the patient's evolution in their medical history. Fig. 3 depicts the diagram of integration of the four web services comprising the SOA, including their entries, processes and outputs.

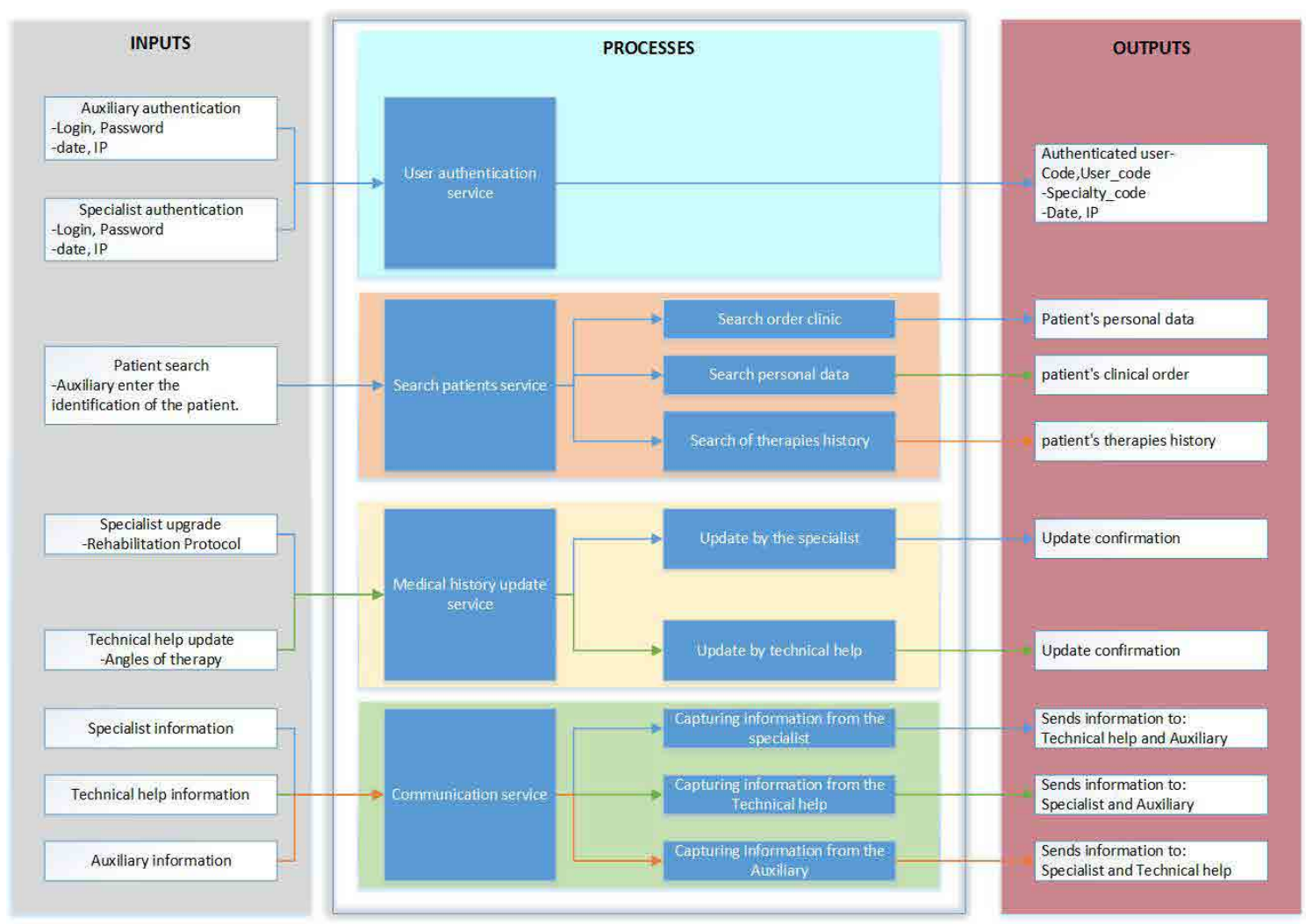

Fig. 3. Process diagram of the web services for a tele-operated rehabilitation system.

\section{RESULTS}

To perform the functional tests, a functional prototype of the architecture was implemented, which was composed of the specialist's PC, the auxiliary's PC, and the technical assistance (Fig. 4). The functional testing of the system evaluated and validated the behavior of the information flow between the specialist, the auxiliary and the database, based on the updates of the interfaces and the information stored in the database.

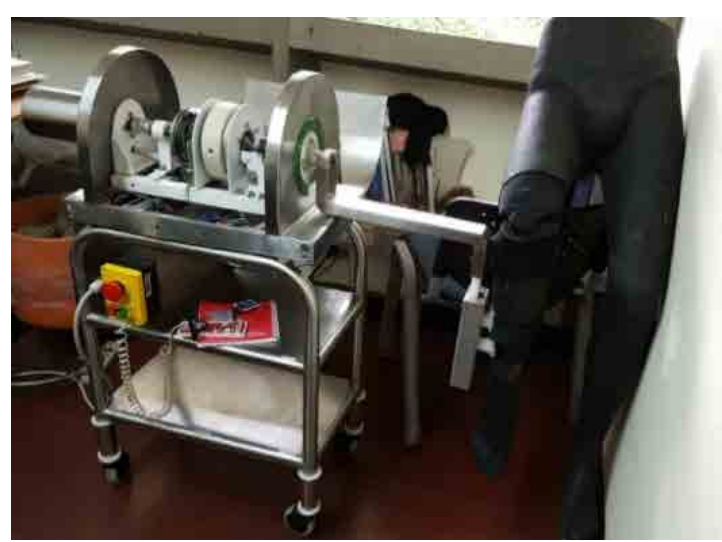

Fig. 4. Technical assistance for rehabilitation of knee. 
Here, we present the functional testing of the system behaving in an ideal way, that is, without submitting any novelties when providing the service. This operation starts with the users' authentication, where the specialist and auxiliary are registered in the graphical interface by entering the login information and password (Fig. 5). The authentication service performs the search in the hospital database, and according to the data supplied by the person, the user is authenticated either as specialist or auxiliary.

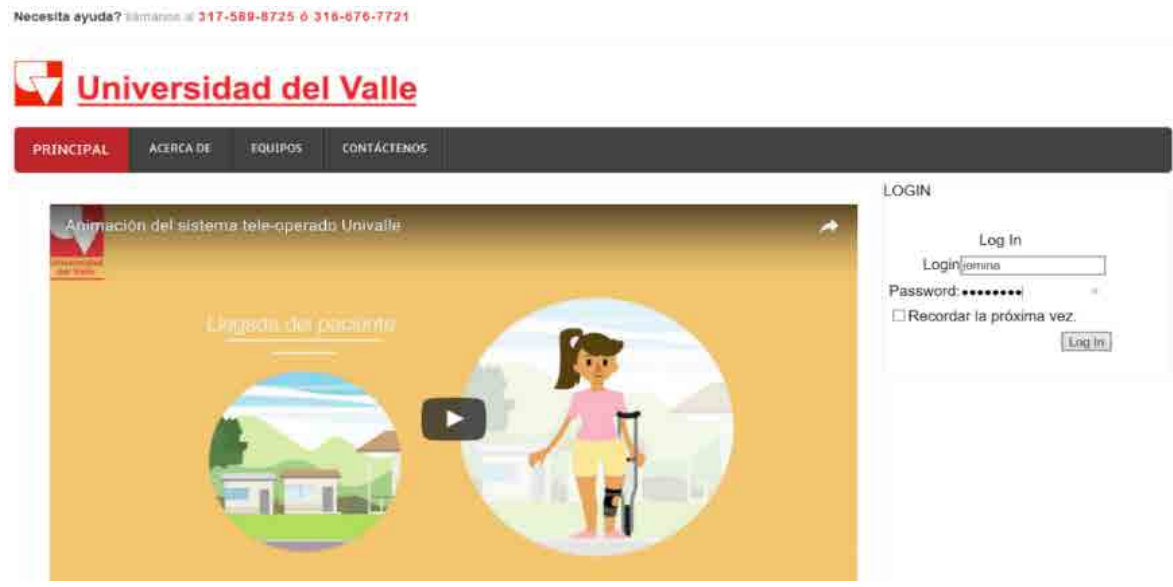

Fig. 5. Screenshot of the user registration process.

After the users are authenticated, the auxiliary enters the patient's identification number, so the patient search service can look for and extract the information related to personal data, order of therapy, and medical history associated with the rehabilitation therapy. This information is visualized in the user's interface for both the auxiliary and the specialist (Fig. 6).

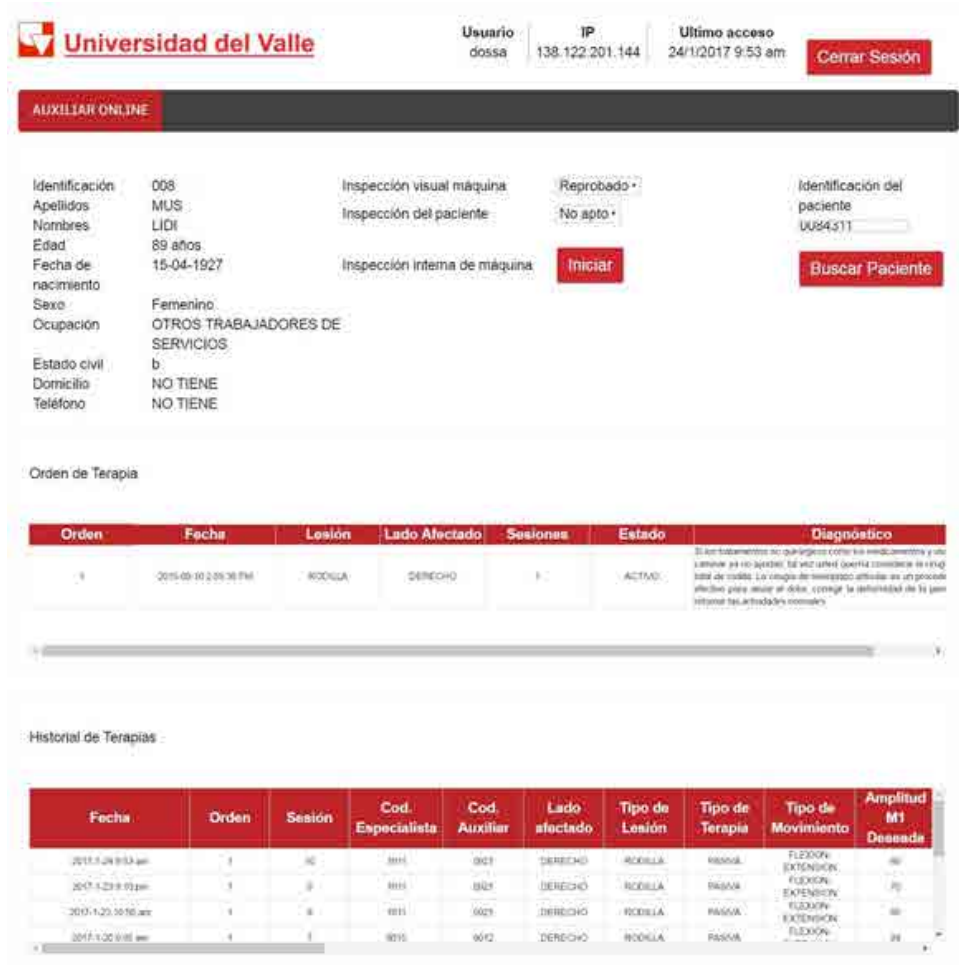

Fig. 6. Screenshot of the patient's information. 
Fig. 7 shows the configuration parameters defined by the specialist that are loaded in the technical assistance for implementing the tele-operated therapy session.

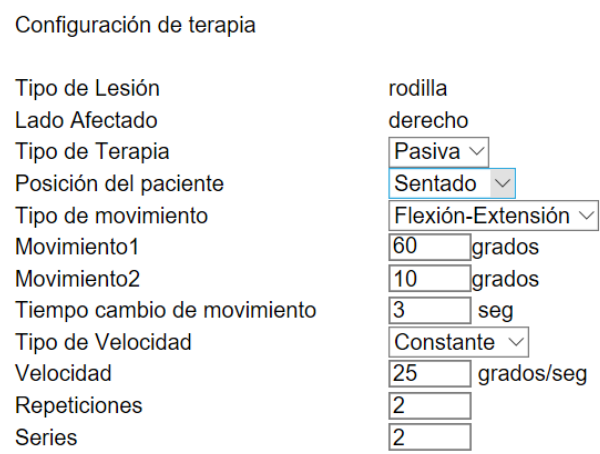

\section{Enviar Protocolo}

Fig. 7. Parameters defined by the specialist

The data achieved by the technical assistance during the therapy is visualized both in the specialist's and the auxiliary's interfaces (Fig. 8). The purpose is to see how the therapy session develops and whether the settings are correct, in comparison with parameters that were programmed in the technical assistance.

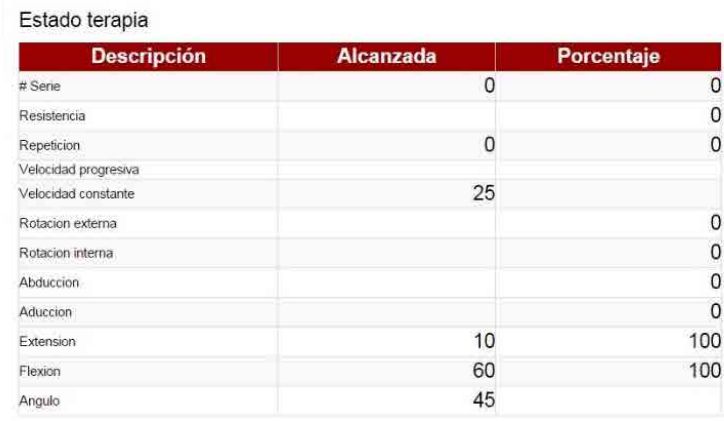

Fig. 8. State of the therapy visualized in the specialist's and the auxiliary's interfaces.

The technical assistance sends permanent information to update the database and, in this way, the treatment of each patient in rehabilitation therapy can be traced. Once the technical assistance executes the entire therapy scheduled by the specialist, it sends a therapy completion message to the specialist's and the auxiliary's interfaces.

\section{Conclusions}

The use of new technologies, such as the internet, for medical applications provides accessibility advantages, so the patients can easily access the medical service and the specialists can access the information on their patients, thus reducing the accessibility barriers.

The SOA approach for tele-operating technical assistance ensures that the application can be integrated regardless to the hardware and/or software; it also promotes the flexibility and scalability of the system, which allow users to tele-operate any type of machine without changing the architecture, just modifying some modules. On the other hand, this system can be expanded because in the future more services could be added to the architecture, in such a way that the initial architecture can be reused either to develop a different application, or to complement it.

Proposing an architecture allows the system to be applied to different musculoskeletal lesions in different joints, because this architecture characterized each articulation according to the degrees of freedom and the maximum and minimum angles defined by the anatomy and biomechanics of the articulation. In addition, this architecture can be implemented in other fields of human health, such as remote diagnosis of patients, management of patient's information, and the possible coordination of this system with the administrative systems of the Colombian health centers.

The architecture proposed for the tele-operated rehabilitation system was validated with real evidence, since the web services were designed and developed in accordance to the architecture defined for the provision of tele-operated rehabilitation services via internet; in addition, the flow of information that runs in the system was managed with a real database of a health center in the city of Cali.

\section{References}

[1] W. W. Dai, V. Vyatkin, and J. H. Christensen, "The application of service-oriented architectures in distributed automation systems," Proc. - IEEE Int. Conf. Robot. Autom., pp. 252-257, 2014. DOI: http:// doi.org/10.1109/ICRA.2014.6906618.

[2] E. Demin, S. Patil, V. Dubinin, and V. Vyatkin, "IEC 61499 distributed control enhanced with cloud-based web-services," in Proc. 2015 10th IEEE Conf. Ind. 
Electron. Appl. ICIEA 2015, pp. 972-977, 2015. DOI: http://doi.org/10.1109/ICIEA.2015.7334249.

[3] R. Gazzarata, F. Vergari, T. S. Cinotti, and M. Giacomini, "A standardized SOA for clinical data interchange in a cardiac telemonitoring environment," IEEE J. Biomed. Heal. Informatics, vol. 18 (6), pp. 1764-1774, 2014. DOI: http://doi. org/10.1109/JBHI.2014.2334372.

[4] J. Eliasson, J. Delsing, H. Derhamy, Z. Salcic, and K. Wang, "Towards industrial Internet of Things: An efficient and interoperable communication framework," in 2015 IEEE International Conference on Industrial Technology(ICIT).pp. 2198-2204, 2015. DOI: http://doi.org/10.1109/ICIT.2015.7125421.

[5] O. Chenaru, A. Stanciu, D. Popescu, V. Sima, G. Florea, and R. Dobrescu, "Open cloud solution for integrating advanced process control in plant operation," in 2015 23rd Mediterranean Conference on Control and Automation (MED). pp. 973-978, 2015. DOI: http://doi.org/10.1109/ MED.2015.7158884.

[6] J. U. Meyer, "Open SOA health web platform for mobile medical apps: Connecting securely mobile devices with distributed electronic health records and medical systems," in 19th IEEE Int. Conf. Emerg. Technol. Fact. Autom. ETFA 2014, 2014. DOI: http:// doi.org/10.1109/ETFA.2014.7005347.

[7] M. B. Doumbouya, B. Kamsu-Foguem, H. Kenfack, and C. Foguem, "Telemedicine using mobile telecommunication: Towards syntactic interoperability in telexpertise," Telemat.
Informatics, vol. 31 (4), pp. 648-659, 2014. DOI: http://doi.org/10.1016/j.tele.2014.01.003.

[8] “CPM de rodilla OptiFlex ${ }^{\circledR}$ 3." [Online]. Available: http://international.chattgroup.com/es/productos/ cpm-de-rodilla-optiflexr-3. [Accessed: 31-Jul-2017].

[9] "Flex-Mate K500." [Online]. Available: http://www. klcflexmate.net/devices.html. [Accessed: 31-Jul2017].

[10] "Artromot-K3." [Online]. Available: http://www. ormed.djoglobal.eu/en_US/ArtromotK3.html. [Accessed: 31-Jul-2017].

[11] "CPM • Continuous Passive Motion: Spectra." [Online]. Available: http://kinetec.fr/en/kinetecselection/cpm-continuous-passive-motion/attellekinetec-spectra-detail.html. [Accessed: 31-Jul-2017].

[12] F. Morales, "Puntos clave en la rehabilitación de rodilla - Artículo de Fisioterapia." [Online]. Available: http://www.efisioterapia.net/articulos/ puntos-clave-la-rehabilitacion-rodilla. [Accessed: 31-Jul-2017].

[13] G. Caicedo, and J. I. García, "Diseño y construcción de una unidad de rehabilitación de hombro teleoperada que integra requerimientos de diseño interdisciplinares," Convoc. interna para la Conform. del banco Proy. Investig. Convoc. 3-2014, 2014.

[14] J. I. García, and G. Caicedo, "Diseño y construcción de una unidad de rehabilitación de rodilla para ser tele-operada que integra requerimientos de diseño interdisciplinares," Convoc. interna para la Conform. del banco Proy. Investig. Convoc. 3-2014, 2014. 